\title{
CASTELLANO ANTIGUO Y ESPAÑOL MODERNO: REFLEXIONES SOBRE LA PERIODIZACIÓN EN LA HISTORIA DE LA LENGUA
}

\author{
Rolf Eberenz \\ Universidad de Lausana
}

\section{Planteamiento general.}

1.1. Quien se ocupa de la historia de la lengua francesa, se sorprende a veces de la normalidad con que los estudiosos de ese idioma manejan los rótulos ancien français, moyen français y français moderne. Como es sabido, los especialistas sitúan la transición del francés antiguo a la etapa meclia entre 1300 y 1350 ; algunos se atienen para ello a una fecha clave de la historia política, el advenimiento de la dinastía de los Valois, en 1328, suceso al que sigue unos años más tarde el comienzo de la Guerra de los Cien Años. Las opiniones están más divididas respecto al término de esta fase media: unos proponen el final del siglo xvI (edicto de Nantes, 1598), otros prefieren las postrimerías del siglo $\mathrm{xv}^{1}$. Aunque la cuestión de los límites siga debatiéndose, puede afirmarse que la tripartición básica de la historia del francés cuenta con una aceptación punto menos que general.

Recuérdese, además, que una división en tres fases suele aplicarse también a la trayectoria del inglés (Old English, Middle English y Modern English) y del alemán (Althochdeutsch, Mittelhochdcutsch y Neuhochdeutsch), división

1 Remito a las reseñas críticas de la discusión en Ch. Marchello-Nizia, Histoire de la langue française aux $X I V^{\circ}$ et $X V^{*}$ siècles, Paris, Bordas, 1979, págs. 3-7; R. Martin, "Pour un dictionnaire du moyen français", en P. Wunderli (ed.), Du Mot au texte. Actes du III ${ }^{e}$ Colloque International sur le Moyen Français, Tübingen, G. Narr, 1982, págs. 1415, y G. Eckert, Sprachtypus und Geschichte. Untersuchungen sum typologischen Wandel des Französischen, Tübingen, G. Narr, 1986, págs. 7-10; los tres autores hacen un balance de las opiniones emitidas hasta el momento, pero sólo G. Eckert se refiere brevemente a los problemas teóricos de la periodización (véase 3.1.). 
que en ambos casos ha sido avalada por hechos tanto sociopolíticos como propiamente lingüisticos ${ }^{2}$.

1.2. En estos tres dominios lingüisticos, la discusión sobre la periodización ha suscitado el interés de los principales historiadores de la lengua, aunque se nota, sobre todo en los trabajos más antiguos, un cierto déficit teórico.

Sorprende, en cambio, la ausencia del tema en la mayoría de los manuales. repertorios y estudios monográficos sobre el español. Según la concepción más difundida en la filología hispánica, la evolución del castellano transcurre en dos etapas, una antigua y otra moderna. La primera va de los origenes hasta fines del siglo $\mathrm{xv}$, la segunda desde el siglo xVI hasta nuestros días. Aquí también, la divisoria entre los dos períodos se funda en unos sucesos de gran trascendencia política: la unión de Castilla y Aragón, la conquista del reino de Granada y el descubrimiento de América. En el plano cultural, estos años constituyen el umbral del Siglo de Oro: la lengua se beneficia de una nueva estética literaria, convirtiéndose al mismo tiempo en objeto de estudio de los humanistas y en instrumento de una incipiente cultura nacional, según lo inanifiesta Antonio de Nebrija en el prólogo de su famosa gramática. Ahora bien, estos datos no siempre se mencionan explícitamente y aún menos se someten a una reflexión crítica. Entre las pocas excepciones cabe mencionar a R. J. Cuervo, quien señala en la introducción a su Diccionario de construcción y régimen que eligió el año 1500 como límite del período preclásico debido al afianzamiento de la unidad política y al auge de la cultura cortesana que se produjo durante el reinado de los Reyes Católicos ${ }^{3}$.

1.3. Conviene no olvidar que Cuervo se habia propuesto elaborar un repertorio - valga la paradoja - histórico a la vez que normativo. Su objeto principal consistía en reunir unos materiales lo suficientemente abundantes como para que permitiesen codificar la lengua contemporánea; la documentación histórica clebía, pues, proporcionar elementos de decisión para la selección y depuración de los múltiples usos existentes en el español decimonónico de ambos hemisferios. Las pautas venían dadas por los clásicos del Siglo de Oro. Desde tal punto de vista, los textos anteriores al siglo xvi te-

2 Para estos idiomas, véanse J. Schildt (ed.), "Zur Periodisierung der deutschen Sprachgeschichte. Prinzipien-Probleme-Aufgaben", en Linguistische Studien, Reihe A, Arbeitsberichte, 88 (Berlin, Akademie des Wissenschaften, 1982); H. H. Meier, "'Frühneu': Englisch und Hochdeutsch", en .Amsterdamer Beiträge zur ältcren Germanistik, 20 (1983), págs. 96-100, y H. Wolf, "Die Periodisierung der deutschen Sprachgeschichte", en W. Besch et al. (eds.), Sprachgeschichtc. Ein Handbuch zur Gieschichte der deutschen Sprache und ihrer Erforschung. t. I, Berlin, de Gruyter, 1984, págs. 815-823.

3 R. J. Cuervo, Diccionario de construcción y régimen $(D C R)$, t. I, Paris, A. Roger \& F. Chernoviz, 1886, pág. Xliv. 
nian sólo un valor relativo, a modo de balbuceos que prefiguraban la perfección del lenguaje clásico. De acuerdo con estos principios, Cuervo decidió presentar las citas de autores medievales en apéndice, al final de cada entrada.

Pese al espíritu filológico que le animaba a él y a su época, el gran hispanista colombiano se sitúa asi en la línea iniciada por el Diccionario de autoridades de la Real Academia, línea que marcó en cierto modo todo el discurso lingüístico del siglo xviII: sus representantes tenían la sensación de que lo mejor de la civilización hispánica pertenecía ya al pasado y que era imposible igualar las creaciones artísticas de aquella época. En la obra de Cuervo y de otros filólogos de su tiempo se manifiesta, por una parte, ese mismo historicismo tan característico del siglo xıx, que originó en las ciencias humanas una visión esencialmente retrospectiva: el lingüista pasó a considerarse un conservador de museo, encargado de desempolvar los vocablos y las construcciones más venerables del idioma. En cuanto a la filologia hispánica, hay que tener en cuenta, además, un cierto pesimismo relacionado con el estado de depresión política y económica en que a la sazón se encontraban los países de habla española. Insisto en estos aspectos porque me parece que el $D C R$ de Cuervo, con su relativa minusvaloración de lo muy antiguo y lo muy moderno, además de su fijación un tanto excesiva en la lengua patrón peninsular y especialmente castellana ${ }^{4}$, es una realización típica de su época; lo cual no menoscaba en nada el mérito de este excelente diccionario histórico. Es, finalmente, de justicia agregar que el equipo que actualmente continúa la obra procura remediar estas deficiencias ${ }^{5}$.

1.4. Después de esta ojeada a las concepciones de Cuervo, conviene examinar la posición de $\mathrm{R}$. Menéndez Pidal, maestro de una de las orientaciones más fecundas de la filología hispánica. Para ello debe tenerse en cuenta que don Ramón no se dedicó primordialmente a la lexicografia, disciplina donde el problema de la periodización resulta más complejo, sino a la fonética histórica; además, su atención se centraba preferentemente en los orígenes del idioma, tema de uno de sus libros más célebres. Desenterrar y analizar con el instrumental del filólogo los textos más antiguos del castellano, describir la transición del latín al romance, evaluar los factores culturales y politicos que determinaron la elevación del castellano a lengua de cultura, he aquí sus principales preocupaciones. En cuanto al tema que estamos estudiando, cabría esperar algunas precisiones de su Manual de gramática española ${ }^{6}$.

- Véase J. A. Porto Dapena, Elementos de lexicografia. El "Diccionario de construcción y régimen" de $R$. J. Cuervo, Bogotá, Instituto Caro y Cuervo, 1980, pág. 121.

5 J. A. Porto Dapena, Elementos de lexicografía, págs. 202 y sigs.

6 R. Menéndez Pidal, Manual de gramática española, Madrid, Espasa-Calpe, $1966^{19}$. 
Sin embargo, parece que la periodización de la trayectoria de la lengua no constituía un problema importante para Menéndez Pidal. Así es que el primer capítulo del libro versa casi exclusivamente sobre la formación del castellano a partir del latín y sobre los elementos constitutivos del léxico (voces patrimoniales, cultismos y palabras alógenas). En el párrafo 35 bis, titulado Pronunciación del español antiguo, aparece, salvo error, la primera mención explícita de la distinción entre "lengua antigua" y "lengua moderna", pero todavía sin definición de ambos términos. Lo que éstos significan puede colegirse de algunos pasajes posteriores donde se contraponen la "ortografía antigua" y lo "escrito a partir del siglo xvir" (§ 47.2a), o "en la Edad Media" y "modernamente" ( $\S 47.2 \mathrm{~b}$ ). Pero otras observaciones de Menéndez Pidal indican que prefería evitar una fijación demasiado categórica de las fases históricas de la lengua. Así leemos que "a partir del siglo xv el español moderno no conoce más consonantes finales que las del punto I: $d, n, l, r$, $\approx(\ldots)$ " $(\S 63.3)$.

Por otra parte, podría argumentarse que los supuestos de la conocida periodización bifásica le parecieron a nuestro autor demasiado evidentes para que creyera necesario exponerlos. Su interés por otros momentos de la historia del español queda, además, patente en sus monografías sobre la lengua de Cristóbal Colón, el lenguaje del siglo xvi, el antagonismo lingüístico entre Madrid y Sevilla y el tema del español de América ${ }^{7}$. Dejó, finalmente, una *Historia de la lengua española inédita ${ }^{8}$, a la que parece referirse cuando, al comienzo de El lenguaje del siglo XVI, afirma proponer "una periodización más corta que el siglo", reservando "para una obra extensa la discusión de [sus] principios" ?.

Se me ocurre todavía otra explicación para la escasa atención que, según todas las apariencias, prestó Menéndez Pidal a la delimitación de las fases evolutivas del español. En el trabajo que acabo de mencionar hallamos unas palabras bastante reveladoras sobre el particular:

"Concebimos $\tan$ cómodamente la historia dividida en siglos que casi no podemos hacer otra división, sobre todo tratándose del lenguaje, cuya evolución conocemos sólo a grandes rasgos" 10 .

7 R. Menéndez Pidal, La lengua de Cristóbal Colón, El estilo de Santa Teresa y otros estudios sobre el siglo XVI, Madrid, Espasa-Calpe, 19685; y "Sevilla frente a Madrid. Algunas precisiones sobre el español de América”, en Estructuralismo e historia. Miscelánea homenaje a André Martinet, t. III, La Laguna, 1962, págs. 99-165.

\& Véase D. Catalán, Lingüística ibero-románica. Critica retrospectiva, Madrid, Gredos, 1974, págs. 125-126.

- R. Menéndez Pidal, La lengua de Cristóbal Colón, pág. 48.

10 R. Menéndez Pidal, La lengua de Cristóbal Colón, pág. 47. 
La primera parte del pasaje se refiere a una periodización esquemática empleada en muchos estudios, principalmente en los que tienen un objetivo cuantitativo. Aplicada a modo de retículo, con unidarles siempre iguales, la división en siglos permite captar el ritmo de las transformaciones, como puede ser la frecuencia creciente de una forma en detrimento de otra. No quiero negar la legitimidad de este procedimiento " $;$ sin embargo, resulta obvio que una construcción apriorística de este tipo no nos dispensa de buscar una periodización que emane del propio devenir de la lengua. También es de gran interés la seguncla parte de la citada frase: Menéndez Pidal renuncia en ella a fijar precisamente esta otra clase de límites que nos interesa aquí, alegando que el conocimiento de la evolución del lenguaje era aún demasiado fragmentario como para que se pudieran trazar fronteras de esta clase. Conforme con su advertencia, el panorama del lenguaje del siglo xvi que el autor ofrece a continuación contiene ante todo una caracterización de los principales estilos literarios de la época; partiendo del esfuerzo consciente de algunas figuras sobresalientes por moldear la lengua según sus ideas estéticas, Menéndez Pidal habla de los períodos de Nebrija, de Garcilaso, de los grandes místicos y de Cervantes y Lope ${ }^{12}$.

Siempre entre los trabajos sobre gramática histórica, conviene señalar el volumen de $\mathrm{H}$. Keniston sobre la sintaxis española del siglo $\mathrm{xvI}^{13}$, único publicado de un proyecto más ambicioso, que había de constar de cuatro partes, dedicadas, respectivamente, a la Edad Media (1200-1500), al siglo XVI, al período moderno (1600-1900) y a la época contemporánea (desde 1900). En relación con el tomo publicado señala el autor que:

"The sixteenth century was chosen as the first in the series because, as a period of transition between Old Spanish and Modern Spanish, it offered the widest body of material for the development of a technique which would be aplicable to the whole history of the language" 14 .

1.5. Después de haberse comentado, en el apartado 1.3., la actitud de Cuervo, se imponen unas referencias al modo en que la Real Academia zanjó el problema de la periodización. Fijémonos, pues, en el primer diccionario

11 Compárese al respecto la observación de A. Yllera, Sintaxis histórica del verbo español: las perifrasis medievales, Universidad de Zaragoza, 1980, pág. 9: "Esta división en siglos es una convención únicamente aceptada por razones de comodidad y por la dificultad de fechar con exactitud algunos textos."

12 Para una apreciación crítica de este trabajo, véase $H$. Flasche, "Ueber die Schwierigkeit einer Periodisierung der spanischen Sprachentwicklung", en Studia historica et philologica in honorem M. Batllori, Roma, 1984, págs. 629-638.

13 H. Keniston, The Syntax of Castilian Prose. The Sixteenth Century, The University of Chicago Press, 1937.

${ }_{14}$ H. Keniston, The Syntax of Castilian Prose, pág. XI. 
histórico de la Corporación ${ }^{15}$, en cuyo prólogo se leen unas precisiones que con ligeras modificaciones se vuelven a encontrar aún en la última edición del diccionario normativo de la Academia ${ }^{16}$ :

\begin{abstract}
"La abreviatura ant., anticuada, indica que la voz o acepción pertenece exclusivamente al vocabulario de la Edad Media; pero también se califica de anticuada la forma de una palabra, como notomia por anatomia, que, aunque usada hasta el siglo xvir, ha sido desechada en el lenguaje moderno. La abreviatura desus., desusada, se pone a las voces y acepciones que se usaron en la Edad Moderna, pero que hoy no se emplean ya."
\end{abstract}

Constatamos que el punto de mira se sitúa en el momento actual, desde el cual las palabras son clasificadas según su grado de modernidad. Con todo, el esquema de periodización de la Real Academia es algo más diferenciado que el de Cuervo, ya que implica, además de la bipartición básica en Edad Media y Edad Moderna, una subdivisión del lapso que transcurre entre 1500 y nuestros días.

El segundo diccionario histórico de la Real Academia ${ }^{17}$ adopta una posición más pragmática, resultado a partes iguales de la tradición y la intuición: los testimonios de cada acepción usual descle la Edad Media hasta hoy se dividen en tres secciones, que corresponden, respectivamente, al periodo medieval, a los siglos xvi y xvII, y a la época comprendida entre $1700 \mathrm{y} \mathrm{el}$ momento actual. Estas tres partes contienen cada una, aproximadamente, el mismo número de citas y se separan tipográficamente por una ligera sangradura; se evitan, en cambio, denominaciones más categóricas, como castellano antiguo, español clásico y similares. Es ésta, sin duda, una solución prudente, si se tienen en cuenta las muchas lagunas de la lexicografia española. Recuérdese también que en la historia del francés los avances en la teoria de la periodicidad se deben precisamente a lo bien explorados que se encuentran los textos medievales gracias a los esfuerzos de Godefroy, Tobler, Lommatzsch y otros.

No es más explícito uno de los principales maestros de la lexicografía hispánica, Joan Corominas. Situándose su diccionario ${ }^{18}$ en la encrucijada entre orientaciones variadas - la etimología en un sentido estricto, la historia de las palabras y la elaboración de un thesaurus panhispánico-, la periodización en cuanto problema de la historia del léxico no llamó la atención del

15 Real Academia Española, Diccionario histórico de la lengua española, ts. I y II, Madrid, 1933-1936; t. I, págs. IX-x.

18 Real Academia Española, Diccionario de la lengua española, Madrid, $1984^{20}$.

17 Real Academia Española, Diccionario histórico de la lengua española, Madrid, 1972 y sigs.

18 Joan Corominas-José A. Pascual, Diccionario crítico etimológico castellano $e$ hispánico, Madrid, Gredos, 1980 y sigs. 
autor. Ello está tal vez relacionado con su marcada preferencia por las etimologias controvertidas, junto a las cuales las voces menos espectaculares, especialmente las derivadas, reciben un tratamiento bastante expeditivo. Así es que las alusiones a las grandes divisiones de la trayectoria del español se resumen en los cuatro rótulos que sin mayores precisiones se encuentran en la lista de abreviaturas del primer tomo: ant. $=$ antiguo, antic. $=$ anticuado (a diferencia de ant., se aplica a "lo usual después de la Edad Media, pero ya no vigente"), $c l$. = clásico y mod. = moderno.

Conviene mencionar también a otro lexicógrafo, un tanto alejado de los métodos más actuales, pero que ha confeccionado varias clases de repertorios: M. Alonso. Me he fijado en sus obras de mayor circulación, el Diccionario del español moderno ${ }^{19}$ y la Enciclopedia del idioma ${ }^{20}$ : en ambas se especifican cuatro etapas, a saber, la medieval (siglos XII a xv), la renacentista (siglos xVI y xVII), la moderna (siglos xviII y xix) y la contemporánea (siglo $\mathrm{xx}$ ). Una división muy parecida es la que propone M. Alvar Ezquerra en su proyecto de un thesaurus del español ${ }^{21}$, donde los línites de las distintas fases se fijan en 1499 (fecha de publicación cle La Celestina), los comienzos del siglo xvin (fundación de la Real Acadenia) y 1898 ó 1939 como posibles umbrales de la época contemporánea.

También puede ser interesante ver cómo han resuelto el problema los lexicógrafos de las primeras etapas históricas del español. Se trata en parte de nombres que acabo de mencionar en un contexto más general: así, M. Alonso ha publicado recientemente un diccionario del castellano medieval ${ }^{22}$, precedido de un resumen de historia lingüística del periodo en cuestión, cuyos límites fija en 1100 y 1499. B. Müller, de la Universidad de Heidelberg e iniciador de otro repertorio de la lengua antigua ${ }^{23}$, sólo toma en consideración los textos anteriores al siglo xv. Y M. Alvar Ezquerra, al presentar el Banco de Datos sobre el Castellano Medieval de la Universidad de Madison ${ }^{24}$, precisa que sus materiales llegan hasta 1500 y proporciona la siguiente justificación :

"La dernière date est, comme toute limite de ce type, arbitraire; cependant, elle n'a pas été déterminée que par une série d'événements historiques (en

\footnotetext{
19 M. Alonso, Diccionario del español moderno, Madrid, Aguilar, $1982^{6}$.

20 M. Alonso, Enciclopedia del idioma, Madrid, Aguilar, 1958.

21 M. Alvar Ezquerra, Proyccto de lexicografía española, Barcelona, Planeta, 1976.

22 M. Alonso, Diccionario del español medieval. Desde las Glosas Silcuses (s. X) hasta el siglo $X V$. Universidad Pontificia de Salamanca, 1986.

${ }_{23}$ Véase B. Müller, "El proyecto de un diccionario del español medieval (DEM) y el estado de la investigación en el campo del léxico del español antiguo", en Cahiers de linguistique hispanique médiévale, 5 (1980), págs. 175-194; cfr. también la introducción al fascículo I de la obra (Heidelberg, Winter, 1987), pág. v.

24 M. Alvar Ezquerra, "Le Dictionary of the Old Spanish Lanyuage (DOSL)", en Cahiers de lexicologic. 35 (1979), págs. 117-132.
} 
1492 la Reconquista prend fin, l'Amérique est découverte et les Juifs expulsés), mais aussi par d'autres faits de caractère philosophique: en 1490 parait l'Universal vocabulario d'Alfonso de Palencia, en 1492 la Gramática et le Vocabulario español-latino de Nebrija, en 1492 ou 1495, le Vocabulario de romance en latin, également de Nebrija, et en 1499, La Celestina, qui ouvre une nouvelle étape de notre histoire littéraire."

En cuanto a los tratados de historia de la lengua, llama la atención el que todos silencien el problema de la periodización. En la práctica, el de R. Lapesa, por ejemplo, ofrece una estructura general de cinco secciones: español arcaico ; época alfonsi y siglo xıv; transición del español medieval al clásico; Siglo de Oro, y español moderno ${ }^{25}$. M. ${ }^{a}$ C. Candau trabaja más bien con el conocido esquema de los siglos ${ }^{26}$; R. Cano Aguilar, autor de un excelente tratado de historia lingüistica del español ${ }^{27}$, adopta esencialmente la tripartición en castellano medieval, español clásico (siglos XVI y xVII) y español moderno (siglos xviII a xx), aunque no entiende dichos períodos como fases de estabilidad, sino como etapas de generalización y consolidación de una serie de cambios ${ }^{28}$.

Una propuesta semejante ofrece la recién publicada gramática histórica de P. M. Lloyd ${ }^{29}$. Sólo el latín aparece, en un principio, descrito como sistema estático; sin embargo, a este capitulo sigue otro titulado "From Earlier to Late Latin", y el español es tratado en dos capitulos epigrafiados "From Late Latin to Old Spanish" y "From Medieval to Modern Spanish", indicio de la perspectiva dinámica que caracteriza estas partes del libro. En cambio, y pese a la alta calidad de la exposición lingüistica, el contexto social y cronológico del castellano antiguo debe desprenderse de una breve reseña sobre la formación histórica de Castilla; nada se dice sobre los textos más representativos de tal estado lingüistico, y esta clase de comentario falta también en el capitulo sobre la transición a la lengua moderna, aunque quizá esté prevista para el tomo II.

25 R. Lapesa, Historia de la lengua española, Madrid, Gredos, $1981^{9}$

28 M. $^{\text {a }}$ C. Candau de Cevallos, Historia de la lengua española. Potomac, Scripta Humanistica, 1985. La tripartición en Edad Media, Siglo de Oro y época moderna aparece también en A. Gómez-Mariana, Die sprach- und literarhistorische Entreicklung des Spanischen, Stuttgart, Klett, 1973.

27 R. Cano Aguilar, El español a travis de los tiempos, Madrid, Arco/Libros, 1988.

28 Cano Aguilar, $o p$. cit., págs. 206-218, 236-250.

29 P. M. Lloyd, From Latin to Spanish. I: Historical Phonology and Morphology of the Spanish Language, Memoirs of the American Philosophical Society, 173, Philadelphia, 1987. 


\section{LAS APORÍAS DE LA historia DE LA LENGUA.}

2.1. Como he intentado demostrar, todas las divisiones cronológicas practicadas hasta el dia de hoy se basan en datos que forman parte del entorno extralingüístico de la lengua y no se refieren casi nunca a transformaciones de la propia estructura del lenguaje. Esto me lleva a detenerme unıs instantes en las posibles bases teóricas de esa disciplina tan escurridiza y reacia a ciertas pretensiones científicas que es la historia de la lengua.

Según puntualiza A. Vàrvaro en su interesante artículo programático sobre la cuestión ${ }^{30}$, la historia de la lengua, tal como se concibe desde el siglo pasado, suele reconstruir un proceso evolutivo dirigido hacia una meta muy concreta, la explicación del espiritu colectivo de una comunidad dada; su razonamiento es forzosamente finalista, en el sentido de una teleología nacional de raiz romántica. En otras palabras: el historiador de la lengua enfoca su objeto desde una perspectiva ideológica propia de la sociedad en que vive.

Las distintas líneas de argumentación de la historiografía lingüística generada por el pensamiento nacionalista pueden observarse sobre todo en el ámbito francés, acerca de cuya trayectoria se han realizado interpretaciones trifásicas del tipo 'unidad' > 'fragmentación' ("feudalismo", "patois") > 'unidad' ("lengua tuna e indivisible"), y otras de dos fases, basadas en conceptos como 'origen' $>$ 'progreso', o 'naturaleza' $>$ 'arte' ${ }^{31}$.

También la historia del español parte de la posición predominante que ocupa este idioma hoy dia en el concierto de las lenguas peninsulares. Se pretende ofrecer una descripción del proceso evolutivo por el que uno de los tantos dialectos románicos de la Península se fue convirtiendo en una gran lengua nacional. Este punto de vista relega a un plano más o menos decorativo no sólo el leonés y el aragonés, dialectos a partir de cierto momento absorbidos por el castellano, sino también otros sistemas lingüisticos que pasaron a funcionar como vehículos de tradiciones nacionales propias, como el portugués y, en menor medida, el catalán, el gallego y el vascuence.

Aunque Vàrvaro parece excluir otros enfoques que el estrictamente teleológico, hay que tener en cuenta la posibilidad de una visión pancrónica que abarque un ámbito geográfico más extenso. Los ejemplos de este enfoque que se me ocurren son el Französisches Etymologisches Wörterbuch, de

\footnotetext{
so A. Vàrvaro, "Storia della lingua: passato e prospettive di una categoria controversa”, en Romance Philology, 26 (1972-1973), págs. 16-51, 509-531; pág. 48.

31 Véase B. Schlieben-Lange, "Wie kann man eine Geschichte der (Minderheiten)Sprachen schreiben? Ueberlegungen zu 'Décadence' und 'Renaissance' des Okzitanischen und Katalanischen", en H. U. Gumbrecht-U. Link-Heer $(\mathrm{Hg}$.$) , Epochenschwellen und$ Epochenstrukturen in Diskurs der Literatur- und Sprachhistoric. Frankfurt, Suhrkamp, 1985, págs. $324-340$.
} 
W. von Wartburg, diccionario que fue concebido como descripción totalizadora del léxico galorrománico (francés, occitano y francoprovenzal, en sincronia y diacronia) ${ }^{32}$, y, en relación con la Península Ibérica, el conocido manual de W. J. Entwistle, The Spanish Language, donde se retratan, uno por uno, los idiomas hispánicos en que se manifestaron importantes tradiciones culturales ${ }^{33}$. Sin embargo, podria argüirse que estas obras no hacen más que llevar los problemas teóricos a otro terreno: ¿en qué se fundan de hecho conceptos como Galorromania e Iberorromania? Según todas las apariencias, en delimitaciones de la geografia física vagamente vinculadas a ciertos rasgos lingüisticos; las discusiones en torno a la tipologia, por ejemplo, del catalán o de las hablas del norte de Italia han puesto en evidencia el riesgo que comportan tales nociones.

2.2. En el caso ideal, la historia de la lengua tal como se cultiva actualmente confronta la evolución de una determinadla sociedad con las transformaciones simultáneas sufriclas por el sistema o los sistemas lingüisticos que utiliza aquélla, con el fin de detectar unas posibles interrelaciones entre ambos procesos. Pero este objetivo último se alcanza sólo en muy contadas ocasiones, ya que los datos disponibles sobre cada una de las trayectorias son siempre fragmentarios. Lo mismo ocurre, por supuesto, en cualquier otra investigación histórica; no obstante, la lengua como instrumento esencial de casi todas las actividades humanas resulta ser un ente mucho más complejo que los que suele estudiar la historiografía general. En tales circunstancias, no queda más remedio que aplicar a la historia de la lengua, hasta donde sea posible, el modelo de la lingüística de variedades. Sólo si consideramos la lengua como arquitectura, esto es, como edificio pluridimensional, llegaremos a dar cuenta de la realidad histórica.

Esto significa, en primer lugar, que debemos relativar la importancia lingüistica de las grandes obras literarias, que suelen acaparar todavía la mayor parte del espacio en nuestras historias de la lengua ${ }^{34}$. Bien sé que no es tarea fácil, sobre todo en lo que respecta a los primeros tiempos del idioma. Pero, al fin y al cabo, Menéndez Pidal trazó el camino en su Origenes del español ${ }^{35}$. Convendría explorar más detenidamente los documentos relativos a otras esferas de la vida, y ello no sólo para el estudio del léxico y la fono-

32 W. von Wartburg, Französisches Etymologisches Wörterbuch. Eine Darstellung des galloromanischen Sprachschatzes. Bonn, 1928 y sigs.

33 W. J. Entwistle, The Spanish Language, together with Portuguese, Catalan and Basque, London, Faber \& Faber, 1969; traducción española: Las lenguas de España: castellano, catalán, vasco y gallego-portugués, Madrid, Istmo, 1969.

34 Véanse las observaciones de J. Mondéjar, "Lingüistica e historia", en RSEL, 10 (1980), págs. 1-48, especialmente pág. 27.

${ }^{35}$ R. Menéndez Pidal, Origcnes del español, Madrid, Espasa-Calpe, $1968^{6}$. 
logia, donde en parte ya se viene haciendo, sino también para el análisis histórico de la morfosintaxis. Por otra parte, poner en tela de juicio la significación social de los textos literarios implica también replantear la relación entre los movimientos literarios y la evolución del sistema lingüístico: quien pretende estudiar, por ejemplo, "la lengua del Siglo de Oro" da por supuesto un cierto isomorfismo entre las transformaciones del idioma y las corrientes artísticas, extremo que hasta el momento no se ha podido probar con argumentos convincentes.

Los movimientos literarios constituyen más bien uno de los numerosos factores sociales que determinan el curso de la evolución lingüistica. Sus criterios estéticos se manifiestan de manera palmaria en los textos poéticos y pueden repercutir, de modo secundario, en el estilo del discurso empleado por los círculos más influyentes de la sociedad. Tal parece haber sido el papel de la literatura, por lo menos hasta el Romanticismo. Por ello, las obras literarias no deben tomarse nunca como los únicos testimonios lingüísticos de una época, incluso cuando ésta resulte relativamente pobre en otros tipos de documentación.

También cabe recordar, a propósito de las etapas más antiguas, que algunos géneros literarios pueden pertenecer a variedades especificas del idioma: son conocidos el dialectalismo más o menos acentuado de la primera lirica castellana, el tono coloquial de ciertos pasajes del Libro de buen amor y del Corbacho, o el estilo arcaizante del Amadis de Gaula y de otras novelas de caballerias ${ }^{36}$.

2.3. Puesto que debemos confesarnos incapaces de aprehender y de representar la totalidad de la vida del lenguaje, se trata de discutir abiertamente los problemas de selección, tanto de los sectores de la realidad lingüistica que se quieran o puedan enfocar como del método más adecuado en cada caso.

Simplificando un poco las cosas, puede afirmarse que las historias de la lengua española acostumbran tratar dos temas de orden extralingüistico: los avatares de la política (cuestiones dinásticas, conflictos bélicos, expansiones territoriales, etc.) y las realizaciones de la cultura literaria, de la que se derivan ciertos modelos para el uso general de la lengua. En cambio, se descuida normalmente gran parte de los aspectos sociales. Pienso, entre otras cosas, en el repoblamiento y colonización de Castilla la Nueva y Andalucía a consecuencia de la Reconquista, la crisis social y dinástica del siglo $\mathrm{xv}$, el auge de Sevilla como centro de los intercambios con los virreinatos americanos, la Guerra de la Independencia, la Revolución de Septiembre y la

36 Compárese al respecto H. H. Meyer, "Frühneu”, pág. 102. 
guerra civil de nuestro siglo, todos ellos temas que la mayoria de los tratados dejan de valorar debidamente.

Algunos lingüistas han señalado que las turbulencias sociales no dan pie a cambios apreciables en la lengua ${ }^{37}$. Es posible que en idiomas sujetos a una normativa férrea, como el francés, las alteraciones sean mínimas. Sin embargo, no cabe duda que, por ejemplo, la militarización de la sociedad, así como las migraciones provocadas por los conflictos armados dejan sus huellas incluso en el habla cotidiana, aunque sea sólo en el plano léxico; buena prueba de ello es el caudal de neologismos procedentes de la retórica política y del lenguaje militar que se propagó al español de cada día desde los tiempos de la Segunda República ${ }^{38}$.

La historia externa tiene repercusiones indiscutibles en la evolución de la lengua. Sin embargo, no basta con señalar unas fechas clave para erigirlas en hitos de la trayectoria lingüistica. Es, por ejemplo, evidente que la diferenciación del gallego y el portugués remonta en último análisis a la independencia portuguesa del siglo xir. Pero de hecho, la lengua de Portugal no empezó a distinguirse nítidamente del gallego hasta la segunda mitad del siglo xiv. Hay razones para suponer que esta clase de desfases se da casi siempre que los sucesos políticos cambian el curso de la evolución lingüística.

Dos factores estrechamente relacionados con la historia social son el desarrollo de la cultura escrita y la acción normativa de ciertas autoridades, tanto en el sentido literario del término como en el político. H. Wolf, después de destacar la importancia de la historia eclesiástica y de las transformaciones sociales para la periodización del alemán, hace hincapié en los he chos culturales (entre los que cuenta, por ejemplo, el comienzo de una tradición escritural o el impacto de la imprenta) y en la extensión social de la educación (patente en la emancipación de las variedades lingüísticas "bajas" o en la generalización de los hábitos de lectura y escritura) ${ }^{39}$. En el ámbito hispánico es más conocida la problemática de la normativa codificada por gramáticos, lexicógrafos e instituciones de planificación lingüística, normativa que en ciertos países ha sido impuesta por el Estado mediante disposiciones legales. Los tratados y repertorios que debemos a este tipo de preocupaciones son interesantes testimonios de un discurso metalingüistico cada vez más diferenciado en las sociedades occidentales. Pueden servir de piedra de toque cuando se quiere verificar hasta qué punto algunos miembros de la

37 Véanse las referencias de F. Lázaro Carreter, "Lenguaje y generaciones", en su volumen Estudios de lingüística, Barcelona, Ed. Crítica, 1980, pág. 236.

38 Remito para este aspecto a R. García Serrano, Diccionario para un macuto, Barcelona, Planeta, 1979; J. F. García Santos, Léxico político de la Segunda República, Universidad Pontificia de Salamanca, 1980; M. Scotti-Rosin, Die Sprache der Falange und des Salazarismus, Frankfurt/Berna, Lang, 1982, etc.

${ }_{39}$ H. Wolf, “Die Periodisierung", pág. 816. 
comunidad empezaron a considerar su idioma como instrumento de cultura digno de mantenerse en buen estado de uso.

En este contexto hay que hacer una referencia a un esquema de periodización aún no mencionado hasta aqui : lo debemos a F. Marcos Marin, quien propuso fijar las etapas históricas teniendo en cuenta las principales iniciativas de reforma lingüistica que se han lanzado a propósito del español ${ }^{40}$. Marcos Marín señala cuatro momentos en que la lengua ha sido objeto de una acción modernizadora: la segunda mitad del siglo xIII (obra de Alfonso el Sabio), el humanismo (cuya vertiente lingüistica inician Palencia y Nebrija). el siglo xviri (fundación de la Real Academia, publicación de su primer diccionario y de la gramática, promulgación de leyes en apoyo a esta obra normalizadora) y el período que arranca de la Segunda Guerra Mundial (creación de la Comisión Permanente de la Asociación de Academias de la Lengua Española, de la Oficina de Información del Español, etc.).

Por seductora que parezca esta propuesta, queda por averiguar en qué medida los textos normativos codifican simplemente usos ya ampliamente aceptados y dónde postulan, al contrario, soluciones que no cuentan todavía con el beneplácito general. Como ejemplo de la segunda hipótesis viene a cuento el caso de la desinencia verbal en -ra (cantara. vinicra, etc.), con sus dos funciones de tiempo y de modo: recuérdese que A. Bello condenó en su gramática ${ }^{41}$ el empleo de la forma como pluscuamperfecto de indicativo, alegando lo molesto de esta polisemia. Sin enbargo, una simple ojeada a la prensa de nuestros días basta para comprobar que ciertos usuarios de la lengua siguen echando en sacu roto la recomendación de Bello. El tercer punto que convendria demostrar, si se acepta la teoría de Marcos Marin, es, por tanto, la influencia de la normativa sobre las distintas variedades del idioma. La elevada proporción de analfabetos en toda Europa hasta tiempos no muy lejanos y el retroceso de la cultura escritural en los últimos decenios, debido al auge de los medios electrónicos, aconsejan aquí una buena dosis de prudencia.

Mencionemos, finalmente, un último tipo de selección, que concierne a la descripción del material lingüístico. Resulta casi trivial decirlo, pero es obvio que cuanto mayor es el corpus, tanto más se reducen las posibilidades de un análisis pormenorizado de la lengua: el investigador debe elegir determinados parámetros —el léxico, la morfosintaxis, la fonética o fenómenos aún más limitados dentro de estos ámbitos- según los cuales pretende estudiar los textos. Y como cada vez más la caracterización de una muestra dada re-

\footnotetext{
40 F. Marcos Marín, Reforma y modernización del español, Madrid, Cátedra, 1979, págs. 77-135.

41 A. Bello, Gramática de la lengua castellana. Madrid, Edaf, 1978, § 720.
} 
quiere un esfuerzo de cuantificación, se trata de evaluar el peso que conviene atribuir a cada parámetro a la hora de trazar el cuadro general.

2.4. Dicho esto, queda por resolver el problema fundamental de la interrelación entre la historia externa y la historia interna de la lengua. Como es de ley en las ciencias humanas, no puede haber certidumbres absolutas ni pruebas concluyentes, aunque sí correlaciones capaces de inclinar la balanza a favor de una $\mathrm{u}$ otra hipótesis.

$\mathrm{La}$ influencia externa sobre la lengua resulta particularmente evidente en el caso de los préstamos léxicos. De hecho, ¿a quién se le ocurriria dudar de que el caudal de arabismos del español se debe de una forma muy directa a la convivencia secular entre cristianos y musulmanes? También se acepta sin más una relación de causa a efecto entre la presencia "franca" en el norte de España (difusión de la reforma cluniacense, establecimiento de colonias galas en ciertas comunidades urbanas, auge de las peregrinaciones jacobeas) y la introducción de una primera oleada de galicismos en el castellano medieval.

Pero estos casos, donde la vinculación de la evolución lingüistica a la historia social es indiscutible, son más bien la excepción que la regla. Puede objetarse, además, que la mayoría de los préstamos mencionados pertenecen al vocabulario terminológico y que éste constituye precisamente una zona periférica del sistema lingüístico. Esta referencia a la dicotomía 'núcleo/periferia' nos recuerda que tradicionalmente se consideran como pertenecientes al meollo de la lengua las estructuras fonológicas y morfosintácticas -entre estas últimas, por ejemplo, los tiempos y modos verbales, la forma y posición de los pronombres clíticos, los conectores, etc.-; sin embargo, no debe olvidarse que también el léxico posee zonas nucleares: pensemos en temas tan esenciales como la evolución de los binomios ser/estar y haber/tener, o la sustitución de verbos básicos de la lengua antigua, como fincar, catar, y prender, por quedar, mirar y tomar, respectivamente.

Todos estos cambios deben analizarse con métodos cuantitativos y desde los primeros brotes de la innovación hasta su generalización completa. Para ello es indispensable tratar por separado tanto los diferentes géneros textuales como los distintos registros de la lengua, teniendo en cuenta que el registro coloquial --cuyas manifestaciones aparecen también en ciertos textos escritos- puede ofrecer soluciones históricamente más avanzadas que el registro formal. Pues bien, la mayoría de estus fenómenos que afectan al núcleo del sistena parecen obedecer a móviles internos, ya que las hipótesis encaminadas a relacionarlos con algún hecho social suelen ser bastante arriesgadas.

2.5. La meta principal de una historia interna de la lengua consiste, por tanto, en reconstruir las fases evolutivas, basando el análisis en una selección 
de parámetros esenciales: lo cual implica que procuremos conocer con precisión las épocas en que se generalizaron los distintos cambios, para verificar en una segunda etapa los decenios o siglos en que tales alteraciones fueron particularmente numerosas. Sólo así llegaremos a saber por fin si la evolución de la lengua se produce a un ritmo siempre igual o si, por el contrario, los cambios se acumulan en determinadas épocas. Si la segunda hipótesis se revelara como exacta, se resolvería el problema de la periodización : formarían entonces periodos históricos cada uno de los lapsos de tiempo en los que, después de un reajuste acelerado de las estructuras, se observase una prolongada fase de estabilidad.

Por otra parte, intervienen en la historia de las grandes lenguas nacionales dos tendencias que parecen condicionar la velocidad del proceso evolutivo; y es que, cuanto más se usa un sistema dado en la confección de textos escritos - sean éstos literarios o meramente utilitarios-, tanto más apremiante se hace la necesidad de una normalización de sus estructuras. Esta progresiva fijación de la lengua patrón impone, lógicamente, un freno a las corrientes innovadoras. Si se tiene en cuenta que a partir del siglo xıx la palabra escrita alcanza un público cada vez más amplio y que con la creciente especialización de las actividades del hombre aumenta también la complejidad de los contenidos que la lengua debe ser capaz de expresar, no sorprende que los idiomas modernos hayan quedado sometidos a una rigurosa estandardización, difícil de imaginar en tiempos anteriores.

Asistimos, pues, a una clara desaceleración del proceso evolutivo de las estructuras nucleares conforme nos acercamos al momento actual; desaceleración compensada por un incremento cuantitativo de las zonas periféricas (terminologías técnicas, jergas sociales, fraseología coloquial, etc.). Los historiadores de la lengua que atienden exclusivamente a los parámetros nucleares se ven, por consiguiente, obligados a fijar para los tiempos más recientes unos períodos mucho más largos que para los primeros siglos. Y si respecto a los períodos más remotos se aducen, por lo común, criterios de delimitación directamente relacionados con la trayectoria del sistema, el fundamento teórico de las etapas modernas suele asentarse en aspectos más bien accesorios, como son, por ejemplo, las oleadas de galicismos y anglicismos que marcan parcialmente la fisonomía del léxico español a partir de los siglos xviri y xix.

2.6. En buena parte de los idiomas nacionales de Occidente la lengua patrón se ha venido perfilando a lo largo de un proceso de selección. Aunque basada en un dialecto histórico concreto, la lengua general se va superponiendo a las hablas vecinas e incorpora poco a poco elementos de estas últimas, para convertirse en una especie de diasistema abierto. El polimorfismo origi- 
nado por los contactos con dialectos afines resulta, sin embargo, inestable. De forma consciente o no, los usuarios prefieren, andando el tiempo, determinadas formas en detrimento de otras. Si la lengua general se muestra muy permeable a las influencias de las hablas vecinas, puede perder la idiosincrasia del dialecto de origen y convertirse en una koiné que participa a partes prácticamente iguales de todas las variedades diatópicas de un territorio. Este fue, con ciertas restricciones, el caso del griego tardio y del alemán moderno.

No ocurrió lo mismo en español, aunque A. López García, en un libro por lo demás lleno de ideas sugestivas, haya interpretado el castellano de los orígenes como koiné forjada por euskaldunes y gentes de habla romance ${ }^{42}$. No es mi intención minimizar la influencia del adstrato vasco; sin embargo, sigo considerando el castellano primitivo como un sistema fundamentalmente románico, muy distinto de las lenguas criollas de otras latitudes.

Como es sabido, las influencias mutuas fueron particularmente tempranas e intensas entre el castellano y el leonés. Pero una vez que el leonés hubo desaparecido del uso administrativo y literario, lo que imprimió a la historia lingüística de la Península su marca inconfundible fue la expansión geográfica del castellano a consecuencia de la Reconquista. Si el castellano se mezcló muy poco con las hablas árabes de las zonas ocupadas, ello debe explicarse forzosamente por una asimilación o emigración rápida de las poblaciones sometidas al dominio castellano. Desde el final de esta fase expansiva (1050-1250), la lengua presenta un grado de homogeneidad que otros idiomas no alcanzarán sino mucho más tarde.

\section{UNA PERIOdización ¿ PARA QUÉ?}

3.1. A estas alturas de la discusión parece oportuno abordlar una cuestión cuyo planteamiento habrá echado de menos más de un lector: ¿en qué consiste de hecho la necesidlad teórica y/o la utilidad práctica de una subdivisión cronológica de la historia de la lengua? Varios son los argumentos en favor de tal cometido.

Por un lado, cualquier investigación histórica apunta, entre otras cosas, a la delimitación de unas épocas dentro de las cuales el objeto de estudio muestre una particular coherencia. La época es la expresión en el tiempo de la unidad situacional. Aunque el objeto se encuentre, bien mirado, en constante evolución, el investigador comprueba que a partir de un momento dado

42 A. López García, El rumor de los desarraigados. Conflicto de lenyuas en la Peninsula Ibćrica, Barcelona, Anagrama, 1985; véase, sobre todo, el resumen en la pág. 54. 
las alteraciones dan pie a un estado cualitativo nuevo. En algunas disciplinas se ha trabajado con los conceptos de equilibrio y desequilibrio: unos cambios sectoriales empiezan a poner en entredicho el buen funcionamiento del sistema, que sufre entonces una reestructuración encaminada a eliminar la deficiencia.

Este modelo cibernético se aplica en numerosas ciencias históricas (politica, sociología, economía, arte, etc.), pero es dudoso que se pueda trasponer sin más a la lingüistica, ya que en este campo la noción de estructura suscita problemas particularmente espinosos. De hecho, aunque estemos acostumbrados a hablar de las estructuras fonológicas o morfosintácticas, no debemos perder de vista la ambigüedad de estos términos. Lo que hasta ahora se ha sacado en limpio es una serie de estructuras parciales - el cuadro fonológico, los sistemas pronominales, los paradigmas verbales, ciertos campos léxicos y semánticos, etc.- Pero no quedan nada claras la interacción entre estas subestructuras, así como la función de las zonas que no se dejan integrar en ninguna de ellas. E incluso en fonología, donde el estructuralismo probó primero su capacidad explicativa, me atrevo a dudar de que la supuesta alternancia de equilibrio y desequilibrio corresponda a una realidad palpable. Aunque J. Gilliéron nos familiarizó con la idea de la terapia verbal, es fácil comprobar que las situaciones de cambio, durante las cuales coexisten dos o más formas sinónimas, pueden durar siglos. Si este polimorfismo estorbara seriamente el funcionamiento del lenguaje, la sustitución de las formas tradicionales por las innovaciones se operaría en plazos mucho más breves de los que suelen observarse en realidad. Por ello resulta plausible el parecer de A. Martinet, cuando dice que :

"l'évolution des structures linguistiques ne fait que refléter l'évolution des besoins des usagers. Il n'y a pas contradiction entre le fonctionnement de la langue et son évolution, mais coïncidence. Ce n'est pas un paradoxe de dire qu'une langue change parce qu'elle fonctionne" 4 .

En el lenguaje no parece haber desequilibrios, sino más bien reajustes a menudo lentos $y$, por supuesto, imperceptibles para los hablantes implicados. En este sentido se manifiesta también G. Eckert, al proponer que el criterio para la determinación de las épocas históricas de la lengua podría ser el abandono de diferenciaciones tradicionales y el surgimiento de otras nuevas, esto es, la reorganización del sistema ${ }^{44}$.

3.2. Pero el afán de subdividir el tiempo histórico no es un simple ca-

43 A. Martinet, Evolution des langues et reconstruction, Paris, PUF, 1975, pág. 12; el subrayado es del autor.

44 G. Eckert, Sprachtypus, pág. 7. 
pricho de investigador. Puede suponerse que cualquier hablante medianamente interesado por el lenguaje llega un dia a preguntarse por el antes y el después del sistema que utiliza; porque las diferencias en el habla de generaciones sucesivas no son un descubrimiento de especialistas, sino una experiencia que hacemos todos desde la niñez. De aqui a atribuir a cada una de las generaciones con que convivimos un tiempo marcado por ciertos sucesos de la historia colectiva, no hay más que un paso. Tampoco es forzar demasiado la verdad si identificamos las tres últimas generaciones de la sociedad española contemporánea con los períodos que arrancan de la guerra europea, de la guerra civil y de la Constitución de 1978, respectivamente; y, olvidando un instante que nuestro punto de partida han sido las generaciones, no chocaría demasiado que alguien supusiera para la descripción del español contemporáneo las tres etapas 'entreguerra', 'franquismo' y 'monarquia democrática'.

Esta constatación nos vuelve a colocar de lleno en el dilema de la historia interna y externa, que hemos procurado resolver hace unos momentos. Es a todas luces difícil salvar el escollo de los datos extralingüísticos. Siendo la lengua - también - reflejo de los avatares políticos, sociales y culturale; que vive la comunidad, forzosamente tiene que recordarnos esos hitos.

Quizá podamos solucionar el problema formulándolo de otro modo. Las grandes lenguas nacionales - e incluso algunas minoritarias - son a la vez instrumentos utilitarios y objetos de cultura. Por una parte, es indispensable que funcionen para satisfacción de los usuarios; por otra, las niembros de la comunidad han sido acostumbrados a ver el idioma como una especie de joya de familia que hay que conservar en buen estado y perfeccionar, si cabe. Los dos puntos de vista, el funcional y el cultural, pueden entrar en conflicto: los esfuerzos de los responsables de la planificación lingüística por reemplazar ciertos extranjerismos susceptibles de "enturbiar la limpieza de la lengua" quedan a menudo condenados al fracaso, simplemente porque el anglicismo en cuestión es más breve, más manejable, menos polisémico y por ende más funcional.

Vista desde este punto de mira, la historia interna no es otra cosa que la descripción diacrónica de la lengua en cuanto sistema funcional. A las alteraciones que se descubran a lo largo de los siglos habrá que buscarles entonces unas posibles motivaciones internas y las repercusiones que hayan tenido en otros sectores del sistema. Los temas privilegiados de este tipo de descripción son, lógicamente, los parámetros esenciales que he comentado más arriba.

La historia externa, en cambio, tiene encargada la recogida e interpretación de los materiales lingüísticos relativos, directa o indirectamente, al contexto sociocultural en que se localiza la lengua. A este método se adscribe, por supuesto, el estudio del léxico, especialmente del vocabulario terminológico. Pero la historia externa debe entenderse en un sentido aún más extenso, 
a saber, como análisis de la actuación del hombre frente al lenguaje. No pienso únicamente en acciones normalizadoras, tema clave de la historiografía nacionalista, sino más bien en una apreciación desapasionada de todas aquellas visiones que el hablante ha proyectado sobre la lengua; ideas cambiantes al filo de las corrientes culturales, que unas veces han llegado a ponerse en práctica $\mathrm{y}$ otras se han saldado por un fracaso. Ahora bien, el concepto de hablante tipo es, por supuesto, una simplificación : se trata de considerar los diferentes grupos e individuos de una comunidad, de determinar quién intenta imponer a quién qué usos lingüísticos y de comprobar hasta qué punto se logra tal propósito. Sólo así evitaremos caer en la trampa de ver la historia de la lengua como un camino de perfección nacional.

3.3. Pero me he alejado otra vez de la cuestión de los imperativos que nos imponen algún sistema de periodización. Entre estos motivos hay, al fin y al cabo, unos de orden eminentemente práctico: quien emprende una investigación cualquiera sobre una diacronía parcial - un proyecto lexicográfico, un estudio morfosintáctico--, se ve obligado a definir un lapso de tiempo que permita delimitar el corpus. A partir de aqui, el razonamiento corre peligro de volverse circular: ¿Es preferible fijar a priori un compartimento cronológico, para considerar el objeto de estudio dentro de sus límites? ¿O no es, por el contrario, la propia evolución del fenómeno observado la que debe proporcionar la información sobre los hitos temporales? La paradoja puede resolverse de dos maneras : o se dispone ya de una periodización apoyada en un gran número de hechos estructurales - en cuyo caso nuestro análisis permitirá corroborar, invalidar o relativizar este marco general-, o los esquemas cronológicos al uso son convencionales, con lo cual los resultados de nuestro trabajo serán el primer elemento fiable para una teoría de la periodización más fundada.

\section{Hacia una historia más amplia de la lengua.}

4.1. ¿Cómo hay que proceler entonces, si se quiere que la periodización sea algo más que un encasillado convencional? Una de las conclusiones que se pueden sacar de lo que llevo dicho es que un intento de este tipo debe dar cuenta tanto de la vertiente funcional como de la vertiente cultural de la lengua, lo que significa, sobre todo, que los dos aspectos deben distinguirse cuidadosamente. Para no perdernos en construcciones apriorísticas, parece conveniente tomar como punto de partida de estas reflexiones el aspecto funcional. A continuación reseñaré, pues, algunos fenómenos particularmente elocuentes, con vistas a un enjuiciamiento crítico de la bipartición castellano an- 
tiguo/español moderno. Voy a empezar con la fonología, por ser la subestructura donde la investigación diacrónica ha llegado ya a resultados concluyentes.

4.2. Como es sabido, un cierto número de datos relativos a la historia del sistema fonológico español prueba que, por lo menos en este sector, la conocida divisoria de 1500 carece de toda relevancia. Se trata de cambios conducentes al estado de lengua que, en líneas generales, se ha conservado hasta el día de hoy; cambios que, o se inician antes de 1500 , o se cumplen más allá de esta fecha:

- La aspiración, que reemplazó a la f-inicial, se mantuvo viva en Castilla la Nueva hasta mediados del siglo xvI, para perderse posteriormente 45 .

- No se generalizó hasta bien avanzada la época clásica el segundo fenómeno clave de la historia fonética del español, el ensordecimiento de las sibilantes sonoras:

- La confusión entre los fonemas $/ s / \mathrm{y} / z /$ (-ss- y -s- en las grafías: passo vs. casa) se extendió por Castilla la Vieja hacia 1500 y estaba ya muy arraigada a mediados del siglo xvi. En la misma época, la norma toledana y sus adeptos continuaban preconizando la distinción; pero a fines de la centuria Oudin ya no la enseñaba, y Mateo Alemán rechazó en 1609 la diferenciación ortográfica entre $-s s-\mathrm{y}-s-{ }^{46}$.

-- También en las postrimerías del siglo xvi se consumó el ensordecimiento del fonema / $\hat{z} /$ (-z- en la grafía ; p. ej. : razón), con lo cual éste vino a coincidir con / $\hat{\mathrm{s}} /$ (grafía $-\varsigma-;$ p. ej. : arçón). Como es sabido, en las dos Castillas el archifonema resultante de esta neutralización adoptó la forma de fricativa interdental $/ \vartheta /$, mientras que en Andalucía y en América se confundió con $/ \mathrm{s} /($ seseo $)$. La generalización de $/ \vartheta /$ en gran parte de España se debe, entre otros factores, a la buena acogida que le reservó la corte de Felipe II ${ }^{4}$.

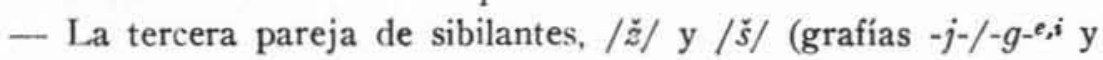

45 R. Lapesa, Historia, § 92.3, y P. M. Lloyd, From Latin to Spanish, págs. 322-326.

46 A. Alonso, De la pronunciación medieval a la moderna en español, Madrid, Gredos, $1967-1969^{2}$, t. I, págs. 7-46; R. Lapesa, Historia, $\$ 53.3,102.2$, y P. M. Lloyd, From Latin to Spanish, pág. 335.

47 D. Catalán, "El fin del fonema $/ \hat{z} /[\mathrm{dz} \sim \mathrm{z}]$ en español", en F. Marcos Marín (coord.), Introducción plural a la gramática histórica, Madrid, Ed. Cincel, 1983, páginas 96-129; P. M. Lloyd, From Latin to Spanish, págs. 331-342; R. Lapesa, Historia, $\S 72.3,92.4-6$, y Estudios de historia lingiiística española, Madrid, Paraninfo, 1985, páginas 249-266. 
- $x$-; ejemplos: fijo y baxo) se transformó aún más tarde. El ensordecimiento de / $\check{z} /$ está atestiguado a partir de 1552 y debía ser general a principios del siglo xvi1. Sin embargo, el resultado de esta neutralización siguió evolucionando, ya que a partir de 1630, aproximadamente, el fonema se pronunciaba como fricativa velar $/ \chi /$, tal como lo conocemos actualmente ${ }^{48}$.

Otra de las reducciones características del sistema fonológico español, el llamado yeismo, se sitúa en la misma época. Después de unos brotes aislados en el reino de Toledo, la confusión de las grafías - $l l-y-y$ - se registra en Andalucía y en América desde el siglo xvI, aunque no se extendió a las demás regiones españolas hasta épocas más recientes ${ }^{49}$.

4.3. En cuanto a la morfosintaxis, es obviamente más difícil demostrar mediante unos cuantos fenómenos representativos que la transición al sistema actual no se acabó de cumplir en el siglo xv. Proporciona ciertos datos al respecto el ya citado libro de $\mathrm{H}$. Keniston; pero hay que tener en cuenta que Keniston, al describir un número relativamente elevado de fenómenos sintácticos, tuvo que renunciar en la mayoría de los casos a un análisis detallado de las alteraciones observadas a lo largo del siglo. Su obra es, pues, más bien un retrato instantáneo de un estado histórico del idioma que un estudio diacrónico de la sintaxis entre 1500 y 1600.

Los paradigmas verbales del siglo XvI se caracterizan todavía por un cierto polimorfismo; para información más detallada remito al tratado de R. Lapesa, quien apunta una larga serie de morfemas que se normalizan bastante tarde en su forma actual (amábades/amábais; tenés/tenéis; matastes/ matástcis; haiga/haya; etc.) ${ }^{50}$. Además, como en otro trabajo he intentado demostrar, uno de los tiempos característicos del castellano medieval, el futuro de subjuntivo, empieza a presentar señales de decadencia durante esa misma centuria, por lo menos en los pasajes que reflejan la lengua coloquial, aunque su eliminación se prolonga hasta el siglo Xviri ${ }^{51}$. También se sitúa entre 1500 y 1600 la desaparición de ser como verbo auxiliar del perfecto compuesto, empleado con verbos intransitivos, y de las formas no soldadas del futuro y el condicional (p. ej.: perderse-á, estarme-ía; etc.) ${ }^{52}$.

\footnotetext{
48 R. Lapesa, Historia, $\S 72.3,92.6-8$, y P. M. Lloyd, From Latin to Spanish, págs. 344-347.

49 R. Lapesa, Historia, § 93.1, y P. M. Lloyd, From Latin to Spanish, págs. 342-344.

so R. Lapesa, Historia, $\S 96.1-3$.

B1 R. Eberenz, "Sea como fuere. Zur Geschichte des spanischen Konjunktiv Futur", en Vox Romanica, 42 (1983), págs. 181-201; versión española en I. Bosque (ed.), Indicativo y subjuntivo, Madrid, Taurus, 1990, págs. 383-409.

82 H. Keniston, The Syntax of Castilian Prose, págs. 450-451 y 112.
} 
Otro sector de la morfosintaxis que empezamos a conocer en sus pormenores es el de las conjunciones. De entre las concesivas desaparecieron, durante los siglos xvi y xvir, elementos como maguer (que), pero que y comoquicr(a) que, al paso que se consolidó definitivamente aunque y cobraron cierta vigencia bien que y si bien ${ }^{53}$. En cuanto a las conjunciones finales, se usó porque con valor tanto causal como final hasta las postrimerias del siglo xVII, momento después del cual cayó en desuso la segunda función ${ }^{54}$. En lo que respecta a las de sentido temporal, la fase de las principales transformaciones se extiende de las últimas décadas del siglo $\mathrm{xv}$ hasta el final de la centuria siguiente: se eliminaron elementos tradicionales, como cada que, tanto que, cuanto que, desque, de que (algunos se conservan regionalmente), mientras se fueron imponienclo siempre que, cada vez quc, apenas ... cuando, no bien ... cuando, al punto que y otros ${ }^{55}$.

4.4. Nada me atrevo a afirmar sobre el léxico, puesto que nos falta todavía una historia del vocabulario básico del español. Es verdad que disponemos ya de algunos estudios diacrónicos sobre determinados campos semánticos: pienso, por ejemplo, en el trabajo de R. Trujillo sobre las facultades intelectuales ${ }^{56}$; el de M. Trapero sobre el campo 'deporte' ${ }^{57}$, y el de I. Corrales Zumbado acerca del área nocional 'edad' ${ }^{58}$. Sin embargo, los períodos que estos autores adoptan como cuadros sincrónicos para la descripción del campo no se libran totalmente de cierta arbitrariedad. En la obra de Corrales tales períodos coinciden con los siglos. Trujillo, después de comentar la evolución diacrónica de varios subsistemas del campo, resume su funcionamiento dentro de unas fases convencionales (de 1870 hasta hoy; 1700-1870; $1500-1700 ; 1200-1500$, y el siglo xII), señalando que "estas fechas son relativamente arbitrarias" 59 . Trapero, en cambio, se preocupa más por el problema de las distintas sincronias y le dedica una serie de reflexiones, entre las cuales destacaré las siguientes:

"Pero aun dentro de la arbitrariedad que supone todo corte sincrónico, se procurará que se correspondan con hechos significativos dentro del proceso de

\footnotetext{
53 J. L. Rivarola, Las conjunciones concesivas en español medieval y clásico, Zeitschrift für romanische Philologie, Beiheft 154, Tübingen, 1976, págs. 1 y 119.

54 E. Rudolph, Das finale Satzgefüge als Informationskomplex, Zeitschrift für romanische Philologie, Beiheft 138, Tübingen, 1973, págs. 15-19.

s5 R. Eberenz, "Las conjunciones temporales del español. Esbozo del sistema actual y de la trayectoria histórica en la norma peninsular", en BRAE, 62 (1982), págs. 289-385.

s6 R. Trujillo, El campo semántico de la valoración intelectual en español, Universidad de La Laguna, 1970.

57 M. Trapero, El campo semántico 'deporte', Universidad de La Laguna, 1979.

58 I. Corrales Zumbado, El campo semántico 'edad' en español, Universidad de La Laguna, 1981.

s9 Trujillo, op. cit., pág. 501.
} 
evolución. Dividir, por ejemplo, el estudio de un campo semántico en tantas sincronías como siglos, resulta manifiestamente irreal, porque la historia de una lengua no se detiene o cambia al final de cada siglo. (...) Por eso creemos que es preferible fijar los cortes sincrónicos en momentos en que el sistema particular del campo que se va a estudiar se desequilibra o se reestructura" 60 .

Los seis periodos en que divide la evolución del sistema se basan, efectivamente, en hechos semánticos y resultan por ello plausibles.

También es interesante para nuestro cometido un estudio más antiguo, el de E. Seifert sobre la historia del binomio haber/tener, puesto que su autora propone ya una periodización a partir de los propios materiales que maneja: asi, por ejemplo, reúne en la segunda parte del artículo el lapso de 1400 a 1550 , "por ser el lenguaje de la primera mitad del [siglo] xvi más parecido al del xv que al posterior a 1550 " ${ }^{61}$. Pero el punto más significativo del trabajo para la historia general del español aparece en su conclusión:

"El siglo xvi es la época de los juegos de palabras. Se conservó haber aún
como verbo incoativo, por ejemplo, en construcciones de deber u obligación,
hasta la época de Cervantes; fue el último baluarte, largo tiempo inexpug-
nable para tener. Desde la segunda mitad del siglo XVI tenemos, más o me-
nos, el estado actual" ${ }^{2}$.

4.5. Los cambios que acabo de reseñar indican que, para la historia de la lengua, el llamado Siglo de Oro no fue una fase de estabilidad, como sugieren ciertas visiones a posteriori, sino, por lo menos en lo que respecta al núcleo del sistema, la última fase formativa. El idioma no se fijó de antemano en su forma más "perfecta" (como sugiere Nebrija), para servir de vehículo a los grandes clásicos, sino que siguió "en ebullición" - para emplear la feliz imagen que E. Lorenzo creó a propósito del español actual-, y esta especie de efervescencia se mantuvo durante prácticamente toda la época áurea. La idea no es completamente nueva, aunque creo que no se ha valorado debidamente ${ }^{63}$. Parece, además, lícito postular desde ahora que el año 1500 no constituye una verdadera frontera en la trayectoria interna del castellano. Todo un conjunto de rasgos esenciales de la lengua moderna se consolida definitivamente en el siglo xvir.

¿Cuándo se inició el reajuste? Para muchos de nuestros parámetros, los primeros testimonios del cambio se remontan al siglo xv. Pero hay otros que apuntan ya a la centuria anterior: entre ellos, por ejemplo, una serie de desi-

80 Trapero, op. cit., págs. 15-16.

61 E. Seifert, "'Haber' y 'tener' como expresiones de la posesión en español", en RFE, 17 (1930), págs. 234-276, 345-389; cita pág. 345 , n. 1.

62 E. Seifert, 'Haber' $y$ 'tener', pág. 384 ; el subrayado de la última frase es mío.

63 La evoca de pasada R. Lapesa, Historia, $\$$ 91.1: "El español áureo, mucho más seguro que el de la Edad Media, era, sin embargo, un idioma en evolución muy activa." 
nencias verbales, que adquieren su forma definitiva a partir del siglo xIv : como formante de la $2 .^{\mathrm{a}}$ persona de pretérito de la conjugación en -ar, -aste va suplantando a -este; en las dos conjugaciones restantes, el plural -iemos es sustituido por-imos, -iestes por-istes; desaparece en el futuro de subjuntivo la $1 .^{\text {a }}$ persona de singular en -o (p. ej. : fuero); en el imperfecto, -ía se hace más frecuente que -ie, y el participo perfecto en -udo se vuelve a perder, después de haber gozado de la preferencia de Alfonso el Sabio y de sus colaboradores ${ }^{64}$.

4.6. Antes de continuar en esta linea de argumentación, me permito una digresión sobre la historia externa de la lengua. $\mathrm{Y}$ es que, contrariamente a lo que podrian sugerir algunas de mis afirmaciones, no la considero una disciplina superflua. Cinco son, a mi modo de ver, los principales factores socioculturales que incidieron de alguna forma en la evolución del español:

I. Los universos discursivos y los géneros textuales en los que se emplea la lengua.

II. La expansión del dominio lingüistico, a consecuencia de las conquistas políticas.

III. La actuación legislativa de las autoridades políticas y/o eclesiásticas en relación con la lengua.

IV. El manejo consciente de la lengua con fines estéticos (literatura, filosofía de la lengua).

V. Los contactos e intercambios con otras comunidades lingüisticas.

En cuanto al primero de estos temas, es el lugar donde deberían comentarse los "orígenes" del idioma, es decir, su aparición en la documentación juridica y administrativa, así como en ciertos géneros literarios; también pertenece a esta temática la extensión de su uso a crónicas y tratados científicos, tal como la propugnó Alfonso el Sabio. Ella podría aprovecharse, finalmente, para el análisis de las relaciones entre el castellano y las demás variedades peninsulares. Con todo, parece que su importancia para la periodización se limita esencialmente a la Edad Media.

La expansión geográfica, en cambio, es un punto capital en la historia del castellano. Por ello, las fechas de 1085 (incorporación del reino de Toledo), 1250 (término de la reconquista de Andlalucía), 1492 (ocupación del reino de Granada y descubrimiento de América) y 1820 (independencia de las repúblicas hispanoamericanas) tendrian que figurar cle alguna manera en un tratado de este tipo. Su función principal consiste en marcar el punto de arran-

64 Véase H. Schede, Die Morphologie des Verbes im Altspanischen, Frankfurt/ Bern, Lang, 1987, págs. 23, 65, 71, 93, 101 y 113. 
que de una serie de diferenciaciones diatópicas (variedades de Castilla la Nueva, de Andalucía y de América, etc. ${ }^{65}$ ). No está de más recordar que los historiadores del portugués basan, desde hace bastante tiempo, en este esquema el tratamiento de las tres modalidades de su lengua: gallego, portugués peninsular, portugués del Brasil y de Africa.

Respecto a las manifestaciones de la política lingüistica, pueden destacarse principalmente dos momentos: el reinado de Alfonso el Sabio, en que a través de unos textos de alta cultura se puede aprehender una primera normalización de la lengua; y la Ilustración, con la fundación de la Real Academia, la publicación de su diccionario y granática, así como la promulgación de un cierto número de disposiciones legales en favor de la lengua oficial. La importancia de ambas acciones para la historia del español no ofrece dudas. En épocas más recientes ha habido, además, una política lingüística articulada, en torno a las lenguas regionales y la defensa contra influencias foráneas.

Curiosamente, en el Siglo de Oro se buscan en vano testimonios de una normativa de tipo autoritario. En cambio, se advierte un enorme interés intelectual por todas las cuestiones que atañen al lenguaje - estamos en nuestro ámbito temático IV-. Es la época en que Alfonso de Palencia y Antonio de Nebrija componen los primeros y ya muy respetables diccionarios de la lengua; en que el mismo Nebrija redacta la primera gramática española y durante la cual nace una larga serie de obras de crítica lingüistica. Ahora bien, aunque Nebrija dedica su gramática a la reina Isabel y reafirma en ella la idea de la lengua "compañera del imperio", todos estos textos forman más bien parte de una amplia discusión sobre los usos y valores de la lengua que un verdadero discurso codificador como el que se observa en Francia durante los siglos xvir y xviri. Incluso un Juan de Valdés, que en algunas ocasiones arremete con vehemencia contra expresiones divergentes del uso cortesano, presenta en el fondo un muestrario de casos controvertidos: al pedirsele un dictamen sobre esos giros sinónimos, suele rechazar los elementos anticuados o marcadamente regionales. Valdés parece simplemente confirmar unas opciones ya efectuadas por la corte y los grandes literatos de la época.

La cristalización de la norma durante los siglos xvi y xvir se produce, pues, a través de unas elecciones intuitivas, mediante un consenso tácito, pero nunca de modo sistemático ni autoritario. I a codificación sistemática de la norma es, más tarde, obra de la Ilustración. Pero, conı ya hemos visto, los lexicógrafos y gramáticos del xvin realizan ante todo una tría de los usos

65 Sobre América, véase G. L. Guitarte, "Para una periodización de la historia del español de América", en su volumen Siete estudios sobre el español de América, México, UNAM, 1983, págs. 167-182. 
más acreditados por los clásicos. Unifican hasta cierto punto, pero no llegan al rigor depurador de sus colegas franceses.

Los contactos con otras lenguas, finalmente, son también pertinentes para la articulación de la trayectoria del español. Tanto la difusión como el posterior retroceso de determinadas clases de elementos alógenos (arabismos, galicismos medievales y más recientes, lusismos, catalanismos y anglicismos) marcan la coyuntura de la sociedad española en distintos momentos históricos. La existencia de otros lenguas en la geografía peninsular y americana ha venido planteando problemas de diglosia que convierten el mundo hispánico en un fascinante laboratorio sociolingüístico. Cada caso posee sus características peculiares: en unos, el español aparece como el idioma dominante; en otros, como las señas de identidad de grupos sociales oprimidos.

4.7. La importancia de cada uno de estos factores para la andadura de la historia interna (lel español no la podemos evaluar aquí, ya que debe ser objeto de una discusión más amplia. Lo que si se ve por ahora es lo siguiente: las alteraciones que afectan a los llamados parámetros esenciales marcan profundamente la primera parte de la trayectoria de la lengua. Más tarde, se observa en los cambios un ritmo cada vez más lento y, por fin, una estabilización de las estructuras fundamentales. Tal fase de consolidación se sitúa, en español, en la primera mitad del siglo xvir. Su momento final no coincide en absoluto con la cronología de las acciones normativas, pero sí con el agotamiento de la cultura literaria de la época áurea. Habrá que reconocer, pues, que el español adquiere su forma moderna a lo largo de los Siglos de Oro y que su fijación definitiva está de alguna manera relacionada con una pérdida de vitalidad de las actividades culturales en torno a la lengua. Como observa Cano Aguilar al iniciar el capítulo sobre el español moderno, desde el siglo xvirI "las grandes líneas de la estructura idiomática no han variado; ni en el plano fónico ni en el morfosintáctico puede señalarse en este período ninguna alteración fundamental" $"$.

La consecuencia directa para la historia de la lengua consiste en que, como más tarde a partir de 1650 , los parámetros nucleares pierden valor para la evolución del sistema y que la atención del estudioso debe desplazarse entonces hacia zonas más periféricas -el léxico terminológico, las locuciones, la formación de palabras, la estilística, etc.-, los cuales sí continúan cambiando. Ahora bien, a nadie se le oculta que el análisis de estos aspectos resulta incomparablemente más costoso, debido a que las alteraciones se producen, sobre todo, dentro de determinadas variedades (diatópicas, diastráticas o diafásicas) o géneros textuales (retórica politica, textos administrativos, tratados

66 Cano Aguilar, op. cit., pág. 255. 
cientificos, periodismo, etc.), por lo que una caracterización global del sistema se hace cada vez más difícil.

Retrocedamos ahora en el tiempo, para fijarnos en los inicios de esa fase de reajuste definitivo que concluye alrededor de 1650: teniendo en cuenta lo resbaladizo del terreno, propongo provisionalmente 1450 como términus post quem (véase 4.2.-5.). Con ello tendríamos una etapa de formación de aproximadamente dos siglos, que coincide, a grandes rasgos, con la época en que España alcanzó un máximo de poder político-económico y de vitalidad cultural. Con todo, el verdadero resorte de las transformaciones lingüisticas no parece que haya que buscarlo ni en las realizaciones políticas de los primeros Austrias ni en la coyuntura literaria, sino en ese ambiente de extrema movilidad social en que viven los pueblos peninsulares desde el final de la Edad Media. Si, en relación con el siglo xv, los historiadores de lengua suelen hablar ante todo del impacto del humanismo sobre la lengua literaria, no debe olvidarse que los contemporáneos se sintieron probablemente más impresionados por la profunda crisis social - lebilidad de los monarcas, luchas nobiliarias, depresión económica y desintegración del sistema de valoresque marcaba ese "otoño de la Edad Media". Además, la mencionada movilidad de los pueblos peninsulares no cesa con la implantación del nuevo orden de los Reyes Católicos, sino que recibe nuevos impulsos con la conquista de Granada y la colonización de América. Como lo ilustra la literatura de la época, los sueños de grandeza colonial y los desengaños ante la degradación de la situación social en la metrópoli solian darse la mano.

4.8. Primera conclusión respecto al problema de la periodización en la historia lingüística: convendría evitar la vinculación a las épocas y edades tradicionales de la historia general, por ser la evolución interna de la lengua un proceso paralelo y sólo muy indirectamente ligado a esta última. Parece, por tanto, improcedente guardar la conocida bipartición en castellano antiguo y español moderno, que apunta de modo demasiado directo al binomio 'Edad Media' vs. 'Edad Moderna' de la historia cultural ${ }^{67}$. Tal división, apoyada en los datos que se han reseñado, sugiere la idea, a todas luces errónea, de que con Cristóbal Colón y Antonio de Nebrija la evolución de la lengua da un salto espectacular y definitivo.

Segunda conclusión: también en la historia interna del español pueden distinguirse tres etapas, susceptibles de subdividirse a su vez. Se advierte una fase antigua, que se extiende entre 1200 y 1450 , aproximadamente, y se caracteriza por una relativa estabilidad de las estructuras esenciales de la

67 Fl mismo reparo hace C. Bousoño acerca de las divisiones de la historia literaria, en su obra Epocas literarias y evolución. Edad Media, Romanticismo y época contemporánca, Madrid, Gredos, 1981, t. I, pág. 112. 
lengua escrita, dentro de los moldes creados por la reforma alfonsina. Le sigue una etapa media, más o menos de 1450 a 1650 , marcada por una transformación más rápida y perceptible de los parámetros fonológicos y morfosintácticos. La conclusión de este reajuste abre, finalmente, una fase moder$n a$, que va de 1650 hasta nuestros días y que presenta de nuevo un sistema esencialmente estable. Las denominaciones están sujetas a modificación, puesto que el término medio ${ }^{68}$ podria evocar el viejo modelo finalista - se trataría de una fase de transición hacia un estado más perfecto-. Otro problema de implicaciones ideológicas, que sólo quiero mencionar de pasada, consiste en saber en cuáles de las tres fases llamamos a esta lengua castellano, y a partir de cuándo la consideramos ya idioma nacional o español. De todos modos, los tres rótulos - antiguo, medio y moderno- podrian darse por buenos, si quedase claro que se refieren al devenir intrinseco del idioma, sin tener relación alguna con lo que los correspondientes lapsos de tiempo significan en la historia politica o literaria. Sólo si nos acostumbramos a ver en el español medio un sistema en ebullición y si nos convencemos de que los autores del Siglo de Oro participaron activamente en el lento reajuste de esta lengua proteica, llegaremos a formarnos una idea exacta de la trayectoria histórica del idioma.

68 Lo utiliza, por ejemplo, L. B. Kiddle, en el título de su trabajo "Sibilant turmoil in Middle Spanish (1450-1650)", en Hispanic Reviezv, 45 (1977), págs. 327-336. 